\title{
HOW SAFE ARE HEALTHCARE WORKERS DURING COVID CRISIS IN NEPAL?
}

\author{
Priyadarshini $M$ \\ Consultant, Department of Obstetrics and Gynaecology, Birat Medical College and Teaching Hospital, Nepal \\ Email: shilpy62@gmail.com \\ https://orcid.org/0000-0003-1916-7225
}

\begin{tabular}{|c|}
\hline Citation \\
Priyadarshini M. How Safe are Healthcare Workers During COVID Crisis in Nepal ? BJHS 2020;5(2)12:1126 \\
\hline
\end{tabular}

DOI: https://doi.org/10.3126/bjhs.v5i2.31528

Dear Editor,

The coronavirus disease 2019 (COVID-19) which has become a global pandemic, is caused by severe acute respiratory syndrome coronavirus 2 (SARS-CoV-2). As per WHO, the first confirmed case of COVID-19 was on $31^{\text {st }}$ December 2019 from Wuhan city, Hubei province of China. ${ }^{1}$ Nepal officially announced its first confirmed COVID-19 case on $24^{\text {th }}$ January 2020, in a 32-year old male who had returned from Wuhan city, China. ${ }^{2}$ Till $31^{\text {st }}$ August 2020, thirtynine thousands and four hundreds sixty confirmed COVID-19 cases have been reported in Nepal with two hundred twentyeight deaths. ${ }^{3}$

To address the situation and combat the COVID crisis, the ministry of health and population of Nepal has even recommended the involvement of the private hospitals to commence the management of COVID cases as per guidelines. Hence, the frontliner going to get exposed to COVID cases are the primary healthcare workers including doctors, nursing staffs, health assistants etc who are going to takecare of the patients. So, here comes the question? How safe are the Healthcare workers during COVID crisis in Nepal? Are Healthcare workers provided with the standard personal protective equipments (PPE) required to combat COVID ? Are Healthcare workers being regularly checked clinically as well as screened by PCR tests? Is the health of Healthcare workers health being properly insured by the respective hospitals or by the government? Recently there are many news of Healthcare workers contracting COVID and dying even in developed countries. More than 900 healthcare workers have died of Covid-19 in United States of America - and the toll is still rising as per the data. ${ }^{4}$ There is a global shortages of masks, respirators, face shields, and gowns, caused by surging demand and supply chain disruptions which have led to efforts to conserve PPE through extended use or reuse, and development of disinfection protocols. There are reports of healthcare professionals contracting infections even with the use of adequate PPE.

Even in Nepal, at least 183 health workers-doctors, nurses, paramedics and lab technicians-deployed in front line to fight Covid-19 have been infected and hundreds of health workers who came into close contact with the infected individuals have been either placed in isolation or quarantine. ${ }^{6}$ In the context of Nepal, with the availability of minimal resources, how wise and how practical is for the Healthcare workers to takecare of COVID crisis.

The answer could be- "It is just a NOBLE PROFESSION !"7"

\section{REFERENCE}

1. Novel Coronavirus (2019-nCoV). World Health Organization; 2020. https://www.who.int/docs/default-source/coronaviruse/situationreports/20200121-sitrep-1-2019-ncov.pdf. Accessed 12 April 2020.

2. Coronavirus disease (COVID-19) outbreak updates and resource material. Ministry of Health and Population; 2020. https:// drive. google. com/drive/folders/ 1SQz5zoNNwYGi_wBeHxnU6sYs261fg1Tx. Accessed 10 April 2020

3. https://www.coronatracker.com/country/nepal/
4. https://www.theguardian.com/us-news/2020/aug/11/covid-19healthcare-workers-nearly-900-have-died

5. https://www.thelancet.com/journals/lanpub/article/PIIS24682667(20)30164-X/fulltext

6. https://myrepublica.nagariknetwork.com/news/183-health-workersin-nepal-infected-with-covid-19-so-far/

7. https://www.valuewalk.com/2019/03/top-10-most-respectedprofessions/ 